\title{
Recent Tendency of Nutritional Therapy for Diabetes Including Low Carbohydrate Diet (LCD)
}

\author{
Hiroshi Bando* \\ Division of Integrative Medicine, Japan
}

*Corresponding author: Hiroshi Bando, Shikoku Division of Integrative Medicine Japan (IMJ), Medical Research, Tokushima, Low

Carbohydrate Diet Promotion Association (JLCDPA), Kyoto, Japan

\begin{tabular}{|c|c|}
\hline ARTICLE INFO & ABSTRACT \\
\hline $\begin{array}{l}\text { Received: 慧 November 10, } 2019 \\
\text { Published: 慧 November 18, } 2019\end{array}$ & $\begin{array}{l}\text { Keywords: Calorie Restriction (CR); low carbohydrate diet (LCD); Look AHEAD (Action } \\
\text { for Health in Diabetes); American Diabetes Association (ADA); Mediterranean Diet }\end{array}$ \\
\hline $\begin{array}{l}\text { Citation: Hiroshi Bando. Recent Tendency } \\
\text { of Nutritional Therapy for Diabetes } \\
\text { Including Low Carbohydrate Diet (LCD). }\end{array}$ & $\begin{array}{l}\text { Abbreviations: CR: Calorie Restriction; LCD: Low Carbohydrate Diet; ADA: American } \\
\text { Diabetes Association; G-I-N: Guidelines International Network; AHEAD: Action for } \\
\text { Health in Diabetes; MACE: Major Cardiovascular Events; MNT: Medical Nutrition } \\
\text { Therapy }\end{array}$ \\
\hline
\end{tabular}

Biomed J Sci \& Tech Res 23(1)-2019.

BJSTR. MS.ID.003833.

\section{Editorial}

As for nutritional therapy, the discussion concerning Calorie Restriction (CR) and Low Carbohydrate Diet (LCD) has been continued. Among them, LCD has shown predominance of efficacy for glucose variability in the diabetes. Author and colleagues have continued clinical research of CR and LCD for years, in which the effect of LCD has been shown [1]. Recent study also indicated the clinical efficacy of LCD by systematic review [2].

On the other hand, the development of standards for guideline would give medical organizations to ensure that recommendations come from various evidence and help medical staffs recognize highquality guidelines [3]. For this process, the Guidelines International Network (G-I-N) becomes a network of guideline developers across the world. Consequently, clinical practice guidelines have been developed for years, and increasingly prominent for broad areas. Among them, those become most beneficial tools for standard decision making in various specialties [4]. A variety of guidelines were categorized by organizations as consensus-based or evidencebased background.

There is a significant report of the Look AHEAD (Action for Health in Diabetes) trial for 4901 participants [5]. They studied the prediction effect of intensive lifestyle intervention for Major Cardiovascular Events (MACE) risk, which include all possible treatment-by-covariate interaction terms. As a result, hazard ratio from quartile 1-4 was $0.64,0.81,1.13$ and 1.37, respectively. It proved to be a significant treatment benefit of intensive lifestyle intervention. Consequently, Look AHEAD study showed the efficacy of reducing cardiovascular events by lifestyle intervention, associated with medical history, physical examination, and laboratory values [5]. There was a significant Consensus report by American Diabetes Association (ADA) in 2019 [6]. It was intended to give clinical professionals basal evidencebased guidance concerning individualizing nutrition therapy for diabetes or prediabetes. Several important strategies for improving and maintaining glycemic targets would include weight control, improving cardiovascular risk factors (blood pressure, lipids, etc.) within individualized targets.

There is not an ideal eating plan or eating type for the management and prevention of diabetes. Because diabetic people show a broad spectrum of diabetes and prediabetes, associated a variety of co-occurring conditions, personal preferences, cultural situations and socioeconomic backgrounds. According to various research for diabetes, there are several choices of eating patterns, which can lead people to healthier goals and quality of life. As one of the standard guidelines, Medical Nutrition Therapy (MNT) was shown as the fundamental diabetes management plan by the ADA. Further- 
more, MNT will be reassessed by several health care providers in frequent times for changing life stages and health situations in the future $[7,8]$. Current consensus report includes guidelines on prediabetes, which was not informed in last edition in 2014 [9]. The characteristic point of this edition would describe prediabetes, type 1 and 2 diabetes mellitus. Nutrition treatment for gestational diabetes and children is shown in other ADA publications, which is Standards of Medical care in Diabetes in 2019 [8].

The present consensus report has revealed the fundamental comment as follows [6]. They are

a. Reducing overall carbohydrate intake for diabetic individuals has demonstrated the most evidence for improving glycemia and may be applied in a variety of eating patterns that meet individual needs and preferences, and

b. For select T2DM adults not meeting glycemic targets or where reducing ant glycemic medications is a priority, reducing overall carbohydrate intake with low- or very low-carbohydrate eating plans is a viable approach. There are some consensus recommendations for eating patterns [6]. They include

a. A variety of eating patterns are acceptable for the management of diabetes,

b. Health care providers should focus on the key factors that are common among the patterns, until the evidence surrounding comparative benefits of different eating patterns in specific individuals strengthens. Some examples are shown, including

c. Emphasize non-starchy vegetables.

d. Minimize added sugars and refined grains, and

e. Choose whole foods over highly processed foods to the extent possible.

The report includes 9 types of nutritional therapy, which are described in the following.

a. U.S. Department of Agriculture (USDA): Dietary guidelines for Americans: it emphasizes various vegetables including fruits, grains lower fat dairy and protein foods [10].

b. Mediterranean Diet: It emphasizes plant-based food, fish, seafood, olive oil, dairy products in low to moderate amounts, typically fewer than 4 eggs/week, red meat and wine in low frequency and amounts and rarely concentrated sugars or honey. It reduces risk of diabetes, A1c value, triglycerides and risk of major cardiovascular events. There are several evidences concerning clinical efficacy $[11,12]$.

c. Vegetarian or Vegan: It emphasizes plant-based vegetarian eating, and devoid all flesh foods without egg or dairy products. It can reduce risk of diabetes, A1c value, body weight, and lower LDL-C and non-HDL-C $[13,14]$. d. Low-Fat: It emphasizes vegetables, fruits, starches, lean protein sources, and low-fat dairy products. It has some effects for reducing risk of diabetes and body weight $[15,16]$.

e. Very Low-Fat: It emphasizes fiber-rich vegetables, beans, fruits, whole intact grains, nonfat dairy, fish, and egg whites and comprises 70-77\% carbohydrate (including 30-60 g fiber), $10 \%$ fat and $13-20 \%$ protein. It would lower blood pressure and body weight [17].

f. Low-Carbohydrate Diet (LCD): It avoids starchy and sugary foods such as rice, pasta, bread, potatoes, and sweets. There is no consistent definition of LCD. In this review, LCD is defined as reducing carbohydrates to $26-45 \%$ of total calories. Its effects include $\mathrm{A} 1 \mathrm{C}$ reduction, weight loss, lowered blood pressure, increased HDL-C and lowered triglycerides [18-20].

g. Very Low-Carbohydrate Diet (VLCD): It often has a goal of 20-50 g of nonfiber carbohydrate a day to induce nutritional ketosis. In this review, a VLCD eating pattern is defined as reducing carbohydrate to less than $26 \%$ of total calories [1820].

h. Dietary Approaches to Stop Hypertension (DASH): It emphasizes vegetables, fruits, and low-fat dairy products and includes whole intact grains, poultry, fish, and nuts. In contrast, it reduces in saturated fat, red meat, sweets, and sugarcontaining beverages. It can reduce risk of diabetes, body weight and blood pressure level [21,22].

i. Paleo: It emphasizes foods theoretically eaten regularly during early human evolution. It includes lean meat, fish, vegetables, shellfish, eggs, nuts and berries, and avoids grains, dairy, salt, refined fats, and sugar. It probably has mixed results and inconclusive evidence [23,24].

\section{Conclusion}

In conclusion, further recommendations for individualization of goals can be observed in the ADA Standards of Medical Care in Diabetes 2019 [8]. Important focus of management for diabetes would be

a. Achieving and maintaining body weight goals and

b. Making delay or prevention of complications of diabetes. This article would be expected to become a reference of nutritional therapy for diabetes in the future.

\section{References}

1. Bando H, Ebe K, Muneta T, Bando M, Yonei Y (2018) Difference of Glucose variability between Low Carbohydrate Diet (LCD) and Calorie Restriction (CR). Asp Biomed Clin Case Rep 2(s1): 4-15.

2. Yamada S, Kabeya Y, Noto H (2018) Dietary Approaches for Japanese Patients with Diabetes: A Systematic Review. Nutrients 10(8): 1080.

3. Qaseem A (2012) Guidelines International Network: Toward International Standards for Clinical Practice Guidelines. Annals of Internal Medicine 156(7): 525-531. 
4. Djulbegovic B, Guyatt G (2019) Evidence vs Consensus in Clinical Practice Guidelines. JAMA 322(8): 725-726.

5. De Vries TI, Dorresteijn JAN, Van Der Graaf Y, Visseren FLJ, Westerink J (2019) Heterogeneity of Treatment Effects from an Intensive Lifestyle Weight Loss Intervention on Cardiovascular Events in Patients With Type 2 Diabetes: Data From the Look AHEAD Trial. Diabetes Care 42(10): 1988-1994.

6. Evert AB, Dennison M, Gardner CD, Lau KHK, Mac Leod J, et al. (2019) Nutrition Therapy for Adults With Diabetes or Prediabetes: A Consensus Report. Diabetes Care 42(5): 731-754.

7. Powers MA, Bardsley J, Cypress M, Paulina Duker, Martha M, et al. (2015) Diabetes self-management education and support in type 2 diabetes: a joint position statement of the American Diabetes Association, the American Association of Diabetes Educators, and the Academy of Nutrition and Dietetics. Diabetes Care 115(8): 1323-1334.

8. 2019 American Diabetes Association. Standards of Medical Care in Diabetes 2019. Diabetes Care 42(1): S1-S193.

9. Evert AB, Boucher JL, Cypress M, Dunbar SA, Franz MJ, et al. (2014) Nutrition therapy recommendations for the management of adults with diabetes. Diabetes Care 37(1): S120-S143.

10. U.S. Department of Health and Human Service. 2015-2020 Dietary Guidelines for Americans ( $\left.8^{\text {th }} \mathrm{Edn}\right)$.

11. Esposito K, Chiodini P, Maiorino MI, Bellastella G, Panagiotakos D, et al (2014) Which diet for prevention of type 2 diabetes? A metaanalysis of prospective studies. Endocrine 47(1): 107-116

12. Estruch R, Ros E, Salas Salvad 'o J, Covas MI, Corella D, et al. (2018) PREDIMED Study Investigators. Primary prevention of cardiovascular disease with a Mediterranean diet supplemented with extra-virgin olive oil or nuts. N Engl J Med 378(25): e34

13. Chiu THT, Pan WH, Lin MN, Lin CL (2018) Vegetarian diet, change in dietary patterns, and diabetes risk: a prospective study. Nutr Diabetes 8(1): 12.

14. Becerra Tom'as N, D'raz L 'opez A, Rosique-Esteban N, Ros E, Buil Cosiales P, et al. (2018) PREDIMED Study Investigators. Legume consumption is inversely associated with type 2 diabetes incidence in adults: a prospective assessment from the PREDIMED study. Clin Nutr 37(3): 906-913.

ISSN: 2574-1241

DOI: 10.26717/BJSTR.2019.23.003833

Hiroshi Bando. Biomed J Sci \& Tech Res

CC) This work is licensed under Creative

Submission Link: https://biomedres.us/submit-manuscript.php
15. Malik VS, Li Y, Tobias DK, Pan A, Hu F (2016) Dietary protein intake and risk of type 2 diabetes in US men and women. Am J Epidemiol 183(8): 715-728.

16. Wing RR, Bolin P, Brancati FL, Bray GA, Clark JM, et al. (2013) Look AHEAD Research Group. Cardiovascular effects of intensive lifestyle intervention in type 2 diabetes. N Engl J Med 369(2): 145-154.

17. Pischke CR, Weidner G, Elliott Eller M, Scherwitz L, Merritt Worden TA, et al. (2006)Comparison of coronary risk factors and quality of life in coronary artery disease patients with versus without diabetes mellitus. Am J Cardiol 97(9): 1267-1273.

18. Sainsbury E, Kizirian NV, Partridge SR, Gill T, Colagiuri S, et al. (2018) Effect of dietary carbohydrate restriction on glycemic control in adults with diabetes: a systematic review and metaanalysis. Diabetes Res Clin Pract 139: 239-252.

19. Van Zuuren EJ, Fedorowicz Z, Kuijpers T, Pijl H (2018) Effects of lowcarbohydrate- compared with low-fat-diet interventions on metabolic control in people with type 2 diabetes: a systematic review including GRADE assessments. Am J Clin Nutr 108(2): 300-331.

20. Snorgaard O, Poulsen GM, Andersen HK, Astrup A (2017) Systematic review and meta-analysis of dietary carbohydrate restriction in patients with type 2 diabetes. BMJ Open Diabetes Res Care 5(1): e000354.

21. Schwingshackl L, Bogensberger B, Hoffmann G (2018) Diet quality as assessed by the Healthy Eating Index, Alternate Healthy Eating Index, Dietary Approaches to Stop Hypertension score, and health outcomes: an updated systematic review and meta-analysis of cohort studies. ] Acad Nutr Diet 118(1): 74-100.

22. Paula TP, Viana LV, Neto ATZ, Leitao CB, Gross JL, et al. (2015) Effects of the DASH diet and walking on blood pressure in patients with type 2 diabetes and uncontrolled hypertension: a randomized controlled trial. J Clin Hypertens (Greenwich) 17(11): 895-901.

23. Jonsson T, Granfeldt Y, Ahreen B, Branell UC, Palsson G, et al. (2009) Beneficial effects of a Paleolithic diet on cardiovascular risk factors in type 2 diabetes: a randomized cross-over pilot study. Cardiovasc Diabetol 8: 35.

24. Lindeberg S, Jonsson T, Granfeldt Y, Borgstrand E, Soffman J, et al (2007) A Palaeolithic diet improves glucose tolerance more than a Mediterranean-like diet in individuals with ischaemic heart disease. Diabetologia 50(9): 1795-1807.

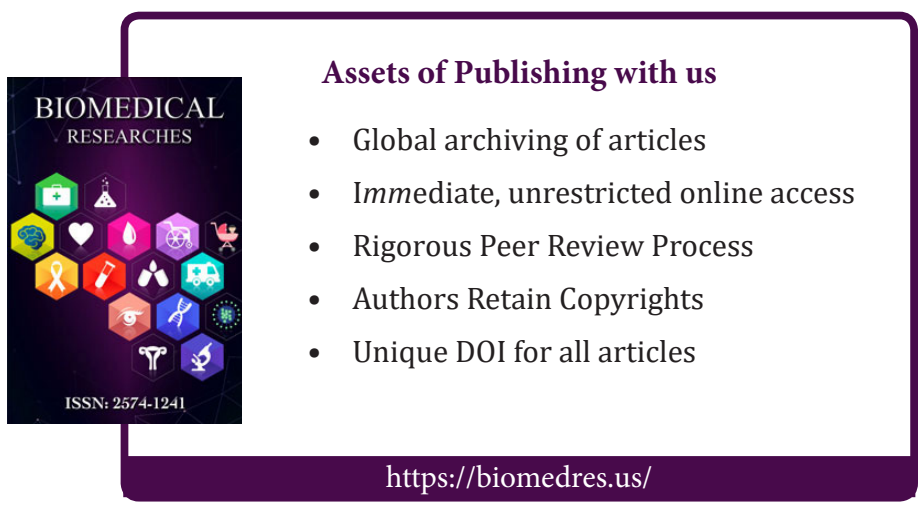

